\title{
Educação de Jovens e Adultos na esfera municipal em Minas Gerais
}

\author{
Fernanda Aparecida Oliveira Rodrigues Silva ${ }^{1}$ \\ ORCID: 0000-0002-8790-0882 \\ Leôncio Soares ${ }^{2}$ \\ ORCID: 0000-0003-4750-2529
}

\section{Resumo}

A ampliação dos encargos subnacionais com a educação básica interroga o protagonismo do poder local desde os anos de 1990. A educação de jovens e adultos (EJA) inserese na agenda dos compromissos municipais e desperta a atenção quanto às formas de atendimento que têm sido realizadas a fim de se cumprir com o direito de todos à educação. 0 artigo apresenta dados da investigação que se preocupou em mapear e compreender ofertas educativas a jovens e adultos empreendidas por dez municípios mineiros. A investigação quanti-qualitativa produziu dados a partir de reuniões com gestores de EJA, seminários de pesquisa, acompanhamento em sala de aula, entrevistas com gestores, professores e alunos, os quais dialogam com a literatura da área do pós Constituição Federal de 1988. A análise dos dados à luz das convergências e das singularidades destaca a afirmativa recorrente de que "A EJA vai acabar" e ressonâncias da frase "Caí na EJA" advindas dos colaboradores da pesquisa. Há reconhecimento por parte dos gestores de que a Educação de Jovens e Adultos tem características próprias. Constata-se que somente esse reconhecimento não tem sido suficiente para amparar uma proposta de EJA, que atenda ao provimento de vaga de educador por meio do concurso público e à formação continuada voltada para as especifıcidades de jovens, adultos e idosos. Ao final, encaminha recomendações a partir das implicações ao perfil do professor como um profissional que afirma poder: "se jogar na EJA".

\section{Palavras-chave}

Educação de Jovens e Adultos - Especificidades - Poder Local - Formação.

\footnotetext{
1- Universidade Federal de Ouro Preto, Mariana, MG, Brasil. Contato: fernandasilva@ufop.edu.br.

2- Universidade Federal de Minas Gerais, Belo Horizonte, MG, Brasil. Contato: leonciogsoares@gmail.com.
} 


\section{Youth and Adult Education within the municipal sphere in Minas Gerais}

\section{Abstract}

The expansion of the subnational responsabilities towards basic education questions the protagonism of the local power since the 1990s. Youth and Adult Education (YAE) is part of the agenda of the municipal commitments and awakens attention as to the forms of care that have been carried out in order to fulfill everyone's right to education. The article presents data from a study that was concerned with mapping and understanding educational offers to youths and adults undertaken by ten municipalities in Minas Gerais. The quantitative-qualitative research produced data from meetings with YAE managers, research seminars, classroom monitoring, interviews with managers, teachers and students. These data dialogue with literature in the area of the post 1988 Federal Constitution. The analysis of the data, in light of the convergences and singularities, highlights the recurring statement that "YAE will end" and resonances of the statement "I fell into YAE" coming from the research collaborators. Educational managers recognize that Youth and Adult Education has its own characteristics. It is evinced that this recognition alone has not been sufficient to support an YAE proposal, which attends to the provision of an educator's position through a public selection process and continuing education focused on the specificities of youths, adults and the elderly. At the end, it makes recommendations stemming from the implications to the teacher's profile as a professional who claims to be able to: "dive into YAE".

\section{Keywords}

Youth and Adult Education - Specificities - Local power - Education.

\section{Introdução}

A preocupação com o estudo escolar de pessoas jovens, adultas e idosas não é recente e tem ampliado seus contornos nas últimas três décadas. Nesse período, presencia-se o incremento da temática em estudos e pesquisas que alargam a concepção de escolarização de jovens e adultos como direito e ao longo da vida, em oposição a de ensino supletivo, que havia se estabelecido desde os anos de 1970.

Em um cenário, não muito distante, de efervescência nacional, há que citar a importância do surgimento dos fóruns de Educação de Jovens e Adultos (EJA) ${ }^{3}$ nos estados. Por meio dos fóruns houve mobilização dos que trabalhavam com a temática em diferentes espaços e instituições; a socialização das experiências vividas; a articulação dos distintos atores e a intervenção na elaboração de políticas públicas de EJA (SOARES,

3 - Maiores informações sobre fóruns de EJA ver Soares (2004); Silva (2008). 
2004). Um dos resultados da pressão exercida pelos fóruns deu-se junto à Secretaria de Educação Continuada, Alfabetização e Diversidade (SECAD) ${ }^{4}$, que levou a inclusão da EJA no Fundo de Manutenção e Desenvolvimento da Educação Básica e de Valorização dos Profissionais da Educação (FUNDEB) ${ }^{5}$, em 2007.

Parte do período de apogeu da EJA pode ser verificado na pesquisa nacional (2003 a 2006) realizada por Sérgio Haddad intitulada Novos caminhos em educação de jovens e adultos, na qual se analisaram a escolarização de jovens e adultos e o desempenho do poder local. 0 estudo aponta “a construção de projetos próprios” (HADDAD, 2007, p. 9) em um contexto cuja tendência foi de descentralização em que teve no Fundo de Manutenção e Desenvolvimento do Ensino Fundamental e de Valorização do Magistério (FUNDEF) (BRASIL, 1996) "o estímulo à municipalização" (HADDAD, 2007, p. 10).

As lutas pela EJA - do direito à garantia de financiamento - culminaram com a realização da VI Conferência Internacional de Educação de Adultos (Confintea), no Brasil (2009), que fortaleceu o crescimento e a projeção nacional em que a EJA encontrava-se (IRELAND, 2013; HADDAD, 2009; SILVA; SOARES, 2008) no período. Esse fato pode ser avaliado pela representativa delegação brasileira que dela participou, com expectativas nos avanços que a EJA poderia ter a partir do Marco da Ação Belém (UNESCO, 2010).

A Meta 12 do documento final da Confintea VI propõe que as "Políticas e medidas legislativas para a educação de adultos precisam ser abrangentes, inclusivas e integradas na perspectiva de aprendizagem ao longo da vida, com base em abordagens setoriais e intersetoriais, abrangendo e articulando todos os componentes da aprendizagem e da educação" (UNESCO, 2010, p. 9). Para Paul Bélanger (2010) era "preciso sair da retórica à ação”, afınal:

[...] no podemos esperar 35 años para que la población adulta pueda incrementar su formación básica, si ése es el lapso de tiempo requerido para hacerlo por la vía única de la escolarización de los jóvenes. Es ahora cuando hay que actuar, al interior de la población adulta. Es hoy día, cuando el 80 por ciento de la población que será adulta en 2021 há dejado y a la escuela y ha culminado su formación inicial. (BÉLANGER, 2010, p. 63).

As saídas da retórica para a ação ainda são pontuais no sistema educacional brasileiro. Em Minas Gerais, por exemplo, a Resolução SEE № 2.843, de 13 de janeiro de 2016 "dispõe sobre a organização e o funcionamento da Educação de Jovens e Adultos/ EJA - cursos presenciais, nas escolas da rede pública estadual de Minas Gerais” (MINAS GERAIS, 2016) e nas escolas dos municípios que não se constituam sistemas próprios de educação. Com base no ensino comum, o documento propõe redução da escolarização básica para dois anos letivos no Ensino Fundamental e um ano e meio no Ensino Médio. A matriz prescrita deixa pouca margem à flexibilização do tempo e do espaço, tanto para o professor quanto para o aluno. A flexibilização "constitui-se como característica fundamental que deve orientar a definição, o planejamento e a sistematização dos projetos de trabalho" (SOARES; VENÂNCIO, 2007, p. 153).

4- Secretaria de Educação Continuada, Alfabetização e Diversidade, criada pelo Decreto n 5.159, de 28 de Julho de 2004, marcava "a incorporação definitiva pelo Estado brasileiro de uma nova agenda de políticas educacionais inclusivas e de valorização da diversidade étnicoracial, regional e cultural do país" (Relatório da Gestão da SECAD 2004, 2005, p. 8).

5- $O$ FUNDEB substituiu a Emenda Constitucional n. ${ }^{0}$ 14/96, regulamentado pela Lei n. ${ }^{0}$ 9.424/96 e pelo Decreto n. ${ }^{0} 2.264 / 97$ - Fundo de Manutenção e Desenvolvimento do Ensino Fundamental e de Valorização do Magistério (FUNDEF). 
Passadas décadas da promulgação do direito de todos à educação na Constituição Federal de 1988 e da Lei de Diretrizes e Bases no 9.394/1996 que concedem a pessoas jovens, adultas e idosas iniciarem ou terminarem a escolarização básica na escola pública, os ordenamentos subnacionais para o setor continuam sendo arenas de disputa política com baixa produção de institucionalidade à EJA.

$\mathrm{Na}$ medida em que o financiamento da EJA foi garantido pelo FUNDEB, esperavase a continuidade do aumento gradativo da procura que vinha ocorrendo na escola. De forma controversa, constata-se decréscimo das matrículas nas redes públicas de ensino do país, conforme o Resumo Técnico Censo (INEP) de 2009 e os estudos de Catelli Jr. e Serrão (2014) para o período de 2002 a 2010. Aos municípios atribui-se o papel de garantidor da escola pública de qualidade, garantidas as condições pedagógicas, materiais, físicas e profissionais. Assim, a partir do exposto, como e de que maneira tem se dado a oferta da EJA no âmbito municipal? A implantação da EJA pelo poder local tem sido tema de interesse em estudos e pesquisas (FÁVER0; RUMMERT; VARGAS, 1999; HADDAD, 2007; CUNHA; RODRIGUES; MACHADO, 2007; MOLL; VIVIAN, 2007; PAIVA, 2006; DI PIERR0, 2017) e em assessorias ${ }^{6}$. Tal literatura aponta que a participação dos municípios no atendimento à EJA tem sido feita com tensão apesar dos ganhos legislativos. A fim de verificar essa questão em Minas Gerais, realizou-se um estudo ${ }^{7}$ sobre o atendimento em escolas públicas municipais.

Este artigo descreve o percurso que levou ao mapeamento da EJA em municípios mineiros e detém-se nos aspectos organizacionais de dez escolas municipais ao analisar as afirmativas recorrentes entre gestores de que "A EJA vai acabar" e da frase "Caí na EJA" entre professores. Por fim, encaminha à conclusão apontamentos analisados do atendimento municipal propondo algumas recomendações.

\section{Aproximações metodológicas entre universidades e municipios}

Para o desenvolvimento da pesquisa, decidiu-se por uma abordagem quantiqualitativa. Segundo Minayo e Sanches (1993), ambas as abordagens são necessárias e complementares. A fim de apresentar a pesquisa aos gestores de 29 municípios de duas regiões mineiras; ouvir deles como o atendimento da EJA vinha acontecendo e escolher os municípios da pesquisa, realizou-se uma reunião em 2015. Nela, o tema da juvenilização sobressaiu-se às demais preocupações apresentadas pelos gestores. Segundo o Gestor C, ${ }^{8}$ são "jovens a partir de 15 anos que as escolas não estão mais querendo, devido aos vários conflitos e pela defasagem idade-série deles”. 0 mesmo participante comenta que o ingresso desses jovens tem levado os adultos ao desestímulo de frequentar a EJA, o que tem sido desafiador, pois precisavam encontrar "um meio termo para tentar buscar esses jovens, pois é Educação de Jovens e Adultos, mas também de adultos.” Em Belo Horizonte,

6- A esse respeito, ver caderno Educação de Jovens e Adultos do Centro Ecumênico de Documentação e Informação (CEDI, 1990).

7- Pesquisa conjunta realizada por duas universidades públicas de Minas Gerais financiada pelo Conselho Nacional de Desenvolvimento Científico e Tecnológico (CNPq), no período de 2014 a 2018.

8- 0 nome dos representantes e suas filiações foram preservados. Os gestores e professores serão doravante denominados Gestor e Professor, respectivamente, seguidos de uma letra que os diferencia. 
frente à recusa dos jovens pela escola, criou-se a alternativa EJA Juvenil ${ }^{9}$, que separou os jovens dos adultos no período de 2014 a 2018.

Em paralelo às reuniões, fez-se levantamento quantitativo das matrículas; do número de escolas e de professores da EJA; visitas exploratórias em escolas e secretarias municipais de educação; busca documental por meio de contato com os gestores e coordenadores de EJA nos municípios e reuniões com representantes municipais em exercício.

A pesquisa ampliou as formas de produção de dados: agregou gestores, oportunizou partilhas de ações e suscitou o desejo de manutenção de um espaço de trocas de experiência. A solicitação do Gestor D sobre a possibilidade "de ter um número maior de encontros para estudar sobre o assunto - está todo mundo com sede, precisando!” conduziu a mais quatro reuniões com os gestores, equipes de pesquisa e um convidado ad hoc, visando a aprofundar temáticas de aspiração geral.

0 interesse dos gestores centrou-se no público juvenil na EJA. 0 professor Juarez Dayrell (Faculdade de Educação - FAE, da Universidade Federal de Minas Gerais (UFMG)) mediou a reunião em junho de 2015 e problematizou a temática perguntando "o que levou esses jovens para a EJA? Em que medida a nossa organização escolar está atendendo às especificidades desses jovens? 0 que os jovens dizem sobre os motivos da sua exclusão? Por que não permanecem?". 0 grupo concluiu que o tipo de escola ofertada é uma réplica da escola do diurno, que não atende às especificidades do público jovem, porque, "se na EJA a gente reproduz a forma escolar do ensino regular não resolve, dá no mesmo”, diz Juarez Dayrell (informação verbal) ${ }^{10}$.

No ano seguinte, em 2016, aconteceram reuniões subsequentes nos meses de abril, junho e julho, que trataram dos desafios encontrados de um modo geral na gestão da EJA nas escolas. Na segunda reunião, o Gestor B avaliou que o encontro o ajudava a "se fortalecer. Vai além da pesquisa. É como uma luta pela melhoria da EJA". Diferentes temas tiveram assento nas reuniões seguintes e o da formação destacou-se entre os demais.

$\mathrm{Na}$ avaliação dos gestores, há pouca visibilidade da EJA nos cursos de graduação e na formação continuada. 0 Gestor J iniciou a sessão com a frase: "recebemos profissionais que estão totalmente despreparados para trabalhar com EJA". 0 Gestor F acrescentou à fala do colega a imagem que se tem do docente da EJA, pois, "os professores do ensino regular sempre acham que os professores da EJA têm uma vida mais tranquila, ficam à toa, mas eles não sabem dos problemas enfrentados, por exemplo, a diversidade dos sujeitos da EJA."

Além das reuniões com os gestores, aconteceram dois seminários de intercâmbio. 0 primeiro em novembro de 2017, com a professora convidada Maria Clara Di Pierro (da Faculdade de Educação da USP - FEUSP) para discutir os resultados parciais da pesquisa. A docente expressou, após leitura do relatório, que "os arranjos escolares parecem demasiadamente rígidos para estudantes adultos/trabalhadores”. Ainda segundo ela, "a demanda de EJA é grande e heterogênea, portanto, a oferta deve ser o mais diversificada possivel para cada grupo". Pensando acerca do papel da EJA na escola, a professora afirma que "a EJA é hoje o lugar do acolhimento de toda diversidade na atualidade escolar, é a "vocação da EJA”". As afirmações de Di Pierro reforçam os achados da pesquisa de que a

\footnotetext{
9- A vigência do projeto EJA Juvenil (Portaria SME 317/2014) na Prefeitura de Belo Horizonte foi até 2018.

10- Fala do prof. Juarez Dayrell, seminário de pesquisa com gestores das redes municipais da região metropolitana de Belo Horizonte, na Faculdade de Educação/UFMG, em 18 de junho de 2015.
} 
EJA poderia ser ofertada também nos turnos matutino e vespertino. Com isso, parcelas do público potencial como o caso das donas de casa, dos adolescentes, dos alunos deficientes e daqueles com jornadas noturnas de trabalho seriam assistidas.

0 segundo seminário aconteceu em maio de 2018, quando o professor Sérgio Haddad (Ação Educativa/ Universidade Caxias do Sul (UCS)) fez a apreciação do relatório final. De início, o professor ressaltou a importância da iniciativa conjunta do estudo, pois, "a ideia de você construir coletivamente uma pesquisa com diversos olhares ajuda ter uma compreensão do fenômeno com toda sua complexidade, quando traz gestor, alunos e professores para discussão.” Disse também, em relação à representatividade de dez municípios, que:

[...] esse jeito de fazer pesquisa é muito importante, em particular nesse momento, por estar colada no município, que acaba vendo o que é mais importante porque pega a maior parte da EJA. Resgata a vida e o que está sendo realizado". (HADDAD, 2018, comunicação oral - dados da pesquisa).

Em relação à forma de sistematização acrescentou "que o relatório é consequência dessa possibilidade de troca. A gente está sempre trazendo coisas novas". Para finalizar, surpreendeu-se "com a quantidade de produção de conhecimento nas universidades executoras da pesquisa construída com quem está na prática”.

Após a aproximação com os municípios, seguiu-se para o aprofundamento qualitativo da oferta com as dez cidades das microrregiões de Belo Horizonte e dos Inconfidentes. Os critérios para a escolha das localidades basearam-se no maior tempo que atendem a EJA; na existência de pesquisas em dissertações e teses sobre a EJA no município; no envolvimento com os fóruns de EJA; na elaboração de algum material didático próprio e na adesão à proposta da pesquisa. Em cada uma das dez localidades selecionou-se uma escola, na qual foram realizadas observações em salas de aulas e entrevistas com estudantes, professores e coordenadores de EJA.

Figura 1 - Mapa da microrregião de Belo Horizonte e dos Inconfidentes

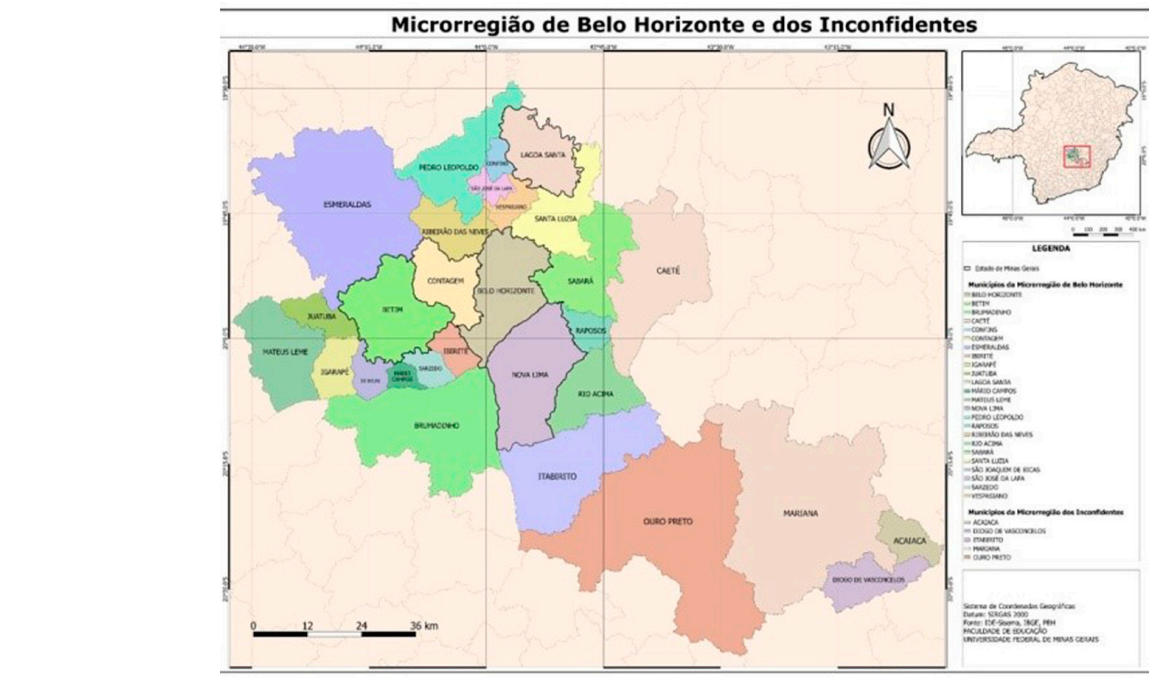

Fonte: Soares; Silva (2018, p. 13). 
Dos resultados da aproximação metodológica com os representantes municipais, destacam-se duas falas recorrentes. Uma, "a EJA vai acabar", vinda dos gestores e outra, a afirmativa dos professores, "caí na EJA". Entendem-se as falas como críticas significativas que devem, portanto, serem aprofundadas.

\section{“A EJA vai acabar” ou querem acabar com a EJA?}

Quais argumentos sustentam a afirmativa vinda de gestores municipais de que "a EJA vai acabar"? No conjunto dos municípios das duas microrregiões investigadas, o direito à educação dos jovens e adultos está efetivado, ou seja, há salas de aula abertas? Alguns fatores colaboram com a construção discursiva de que a EJA sob determinadas circunstâncias vai acabar. Trata-se de um conjunto disperso que incide de forma concentrada e com efeitos duradouros sobre a EJA, pois são concepções e políticas públicas.

A ideia de finitude da população sem escolarização é uma concepção que coincide com as palavras de Darcy Ribeiro - "Deixem os velhinhos morrerem em paz! Deixem os velhinhos morrerem em paz!”, durante o Congresso Brasileiro de Educação em São Paulo (1990), em comemoração ao Ano Internacional da Alfabetização, como se a educação de jovens e adultos fosse sinônimo de alfabetização. 0 então ministro da Educação Paulo Renato Souza (1995-2002), na mesma linha narrativa de Darcy Ribeiro, afirmou que o Brasil fecharia de vez a "fábrica do analfabetismo" por meio da escolarização das crianças. Já o ministro José Goldemberg (1991-1992) reverberou que "o grande problema de um país é o analfabetismo das crianças e não o dos adultos. 0 adulto analfabeto já encontrou seu lugar na sociedade. Pode não ser um bom lugar, mas é seu lugar. Vai ser pedreiro, vigia de prédio, lixeiro ou seguir outras profıssões que não exigem alfabetização”. Além disso, completou: "alfabetizar o adulto não vai mudar muito sua posição na sociedade e pode até perturbar. Vamos concentrar os nossos recursos em alfabetizar a população jovem. Fazemos isso agora, em dez anos desaparece o analfabetismo" (GOLDEMBERG, 1991, n.136, p.4).

É de amplo conhecimento, e as falas dos ministros reforçam, que ao longo da história do Brasil, a escolarização não foi para todos. A obrigatoriedade expressa na Lei de Diretrizes e Bases (LDB) 5.692/1971 fixou o direito à educação para a faixa etária dos 07 aos 14 anos de idade. Dessa forma, parcelas de jovens e adultos da população deixaram de usufruir desse bem social. Portanto, a afırmativa, mesmo que ligada à ideia de que "assim que os analfabetos aprenderem a ler e a escrever" a EJA acaba, é frágil em um cenário de juvenilização da EJA, ou mesmo, porque a educação dos jovens e adultos não é só alfabetização.

Outro fator diz respeito à naturalização da realidade de que na EJA “é assim mesmo" (Gestor F). Segundo os gestores, são poucos os que a procuram e muitos que a abandonam no decorrer do ano. Nesse ponto, os gestores consideram que o abandono é uma questão fora da alçada deles. Uma vez que os dados apresentados entre demanda versus oferta em cada localidade vieram à tona, o argumento do fim eminente da EJA não se sustentou. Afinal, a demanda não é irrisória nem residual, conforme aponta o comportamento das matrículas na EJA no período 2010 a 2016 nas microrregiões. 
Tabela 1 - Panorama das Microrregiões inseridas no Estado e no Brasil

\begin{tabular}{|c|c|c|c|c|}
\hline Local & $\begin{array}{l}\text { População Estimada } 2016 \\
\text { (IBGE) }\end{array}$ & $\begin{array}{l}\text { Demanda EJA (15 e mais) } \\
\text { (Deepask/2010) }\end{array}$ & $\begin{array}{c}\text { Matrículas de EJA EF na } \\
\text { rede municipal } \\
(\text { QEdu/2016) }\end{array}$ & $\begin{array}{c}\text { Matrículas de EJA EF na } \\
\text { rede estadual } \\
\text { (QEdu/2016) }\end{array}$ \\
\hline Brasil & 206.081 .432 & 58.000 .000 & 1.342 .504 & 1.919 .053 \\
\hline Minas Gerais & 20.997 .560 & $5.897 .281^{*}$ & 74.141 & 252.807 \\
\hline \multicolumn{5}{|c|}{ Microrregião de Belo Horizonte } \\
\hline Belo Horizonte & 2.513 .451 & 464.515 & 15.841 & 23.581 \\
\hline Contagem & 653.800 & 140.403 & 3.248 & 2.992 \\
\hline Betim & 422.354 & 90.219 & 2.002 & 2.210 \\
\hline Nova Lima & 91.069 & 17.985 & 399 & 551 \\
\hline Lagoa Santa & 60.787 & 11.906 & 406 & 308 \\
\hline \multicolumn{5}{|c|}{ Microrregião dos Inconfidentes } \\
\hline Ouro Preto & 74.356 & 17.007 & 225 & 715 \\
\hline Mariana & 59.343 & 13.709 & 644 & 131 \\
\hline Itabirito & 50.305 & 12.548 & 248 & 847 \\
\hline Acaiaca & 4.061 & 1.476 & 17 & 91 \\
\hline Diogo de Vasconcelos & 3.918 & 2.012 & 47 & 00 \\
\hline
\end{tabular}

Fonte: Relatório de Pesquisa (SOARES; SILVA, 2018).

Nota: * (http://tabnet.datasus.gov.br/cgi/tabcgi.exe/ibge/censo/cnv/escamg.def)/ 2016.

Se, de um lado, constatamos a efetivação da oferta de EJA em todos os municípios participantes do estudo, de outro, os dados expressos acima informam expressiva atuação dos municípios e que em cada um deles o atendimento está aquém da demanda em potencial. 0 atendimento público da EJA em âmbito nacional cobre menos que 10\% da demanda. No primeiro encontro com os gestores foram apresentados esses dados. A reação geral foi de perplexidade tamanho o desafio de encurtar a distância entre a oferta e a demanda.

A organização do tempo escolar nos municípios é um fator a ser levado em conta quando se trata da redução da oferta de EJA, porque atendem prioritariamente no turno da noite. Há, por certo, aqueles que abrem salas também matutinas e vespertinas, mas são exíguas essas iniciativas. A predominância da oferta no noturno deixa de contemplar a diversidade do público da EJA, que passa a ter somente esse momento para realizar os estudos. 0 direito à educação acaba sendo um tema em disputa na esfera local: pelo financiamento, pelo turno, pelo espaço, pela merenda, pelos livros e pelos professores.

Estudos de Jane Paiva (2006, p. 538) concluíram que "planos estaduais e municipais de educação" estavam por ser construídos "configurando um espaço novo de possibilidades para a inclusão da educação de jovens e adultos no campo dos direitos.” A exceção faz-se aos municípios de Belo Horizonte e Contagem que se organizam como sistemas de educação e gozam da prerrogativa de estabelecer a educação municipal autônoma em relação ao estado. Ambos atendem aos públicos da EJA em espaço não escolar. Em Belo Horizonte, o projeto é denominado de EJA Externa. 0 mesmo município criou em 1991 um centro exclusivo de EJA com atendimento nos três turnos. Isso significa uma 
sede própria, com estudantes só de EJA e a possibilidade de os professores trabalharem somente nessa escola.

Ao contrário da ideia de que "a EJA vai acabar", o que se evidenciou da expressão dos gestores é que o poder local pode acabar com a EJA pela inobservância de um direito (BEISIEGEL, 2006; HADDAD, 1987). A garantia do financiamento da EJA na educação básica, a partir do FUNDEB, deveria sustentar a oferta dos entes subnacionais. Entretanto, Volpe (2010), em estudos sobre financiamento para a EJA em Minas Gerais, alertou que a participação maior dos municípios na gestão e no financiamento da educação não seria suficiente, caso não contassem com a complementação do Estado e da União. Em alguns municípios da amostra, a reduzida capacidade financeira aliada à não vontade política diminui a possibilidade de evolução dos gastos com a EJA.

Ao verificarem-se as formas de atendimento, outro fator que aparece é que alguns municípios apontam reorganização da oferta com tendência à redução do número de salas de aula utilizando a nucleação das escolas. Tal ação, pensada em primeira instância para as escolas do campo, acabou chegando à EJA na esteira da lógica econômica. Segundo os gestores, a nucleação é justificada pela baixa procura dos estudantes, o que, em parte, não é verdade. Se tomarmos os números expressivos da demanda em potencial para EJA em cada município, poderemos indagar quais as razões que impedem ou dificultam o público a buscá-la. Outro aspecto a ser considerado é o fato de que muitos municípios chegam a ter uma dezena de distritos e vilas sob sua jurisdição em vasto território, enquanto outros caracterizam-se por serem cidades dormitórios. Historicamente, o atendimento da EJA próximo ao local de trabalho ou da moradia do estudante tem sido um fator motivador, por reduzir riscos e desgastes dos deslocamentos para uma escola distante. Paschoal Lemme atesta esse fato em 1940, em texto apresentado para concurso.

Constatamos, porém, desde logo, uma porcentagem relativamente pequena de candidatos provenientes das classes operárias, em relação principalmente aos que provinham das profissões ligadas às atividades comerciais. [...] Essas observações, sugeriram-nos medidas tendentes a levar os benefícios da cultura até essas classes, sem dúvida as mais necessitadas dela, tais como a localização dos cursos nos bairros de moradia operária, aproveitamento das sedes das associações de classe onde já está assegurada uma certa frequência, e ainda a instalação de cursos nos próprios locais de trabalho. (LEMME, 2004, p. 77-78).

Manter salas abertas em pequenas localidades ou EJA Externa, ao mesmo tempo em que atende aos estudantes tensiona o referencial de número mínimo por sala estabelecido em leis subnacionais. A organização da EJA, em alguns municípios, baliza-se pelo viés economicista quando se trata de manter em funcionamento várias salas com professores em efetivo exercício. Nesse ponto, vale salientar a concepção do gestor que vê a EJA como gasto e não como direito.

Ainda que a EJA seja modalidade da Educação Básica, não goza das mesmas prerrogativas que o ensino comum. 0 grau de comprometimento do gestor influencia no tratamento que ele recebe no interior das Secretarias Municipais de Educação, a começar pela chamada pública. Foram poucos os municípios da pesquisa realizada que fizeram a chamada pública, o que deixou a população sem a informação de que a EJA estivesse 
sendo ofertada. Nas regiões em que houve busca ativa, fez-se chegar à informação até os possíveis candidatos jovens e adultos. Assim, em lugar da expressão "a EJA vai acabar", constata-se, da maneira como vem sendo conduzida em alguns municípios, que "querem acabar com a EJA".

Há que acrescentar aos demais aspectos a discussão acerca da realidade social. A conjuntura socioeconômica, que tem levado à redução de direitos e a luta pela sobrevivência faz com que a busca pelo trabalho acabe sendo mais necessária do que os estudos. Não são raros os depoimentos de estudantes que relatam dificuldades ou mesmo reprovação de empregadores em apoiar seu retorno aos estudos.

Propostas pedagógicas variadas correspondem ao terceiro aspecto. Em grande parte dos municípios, o desenho curricular diferencia-se pouco do ensino comum, por não serem sistemas próprios de educação. Beisiegel (2006) já anunciava a EJA como réplica da escola convencional, sendo o modelo básico semestral com duração de dois anos para cada segmento do Ensino Fundamental. As disciplinas, de modo geral, seguem a estrutura do ensino comum: língua portuguesa, matemática, história, geografia e ciências. Em algumas redes, há certa rigidez ao cumprimento do horário e da frequência.

Arroyo (2008) é crítico quanto ao modo como a EJA vem se aproximando cada vez mais do modelo escolar e distanciando-se das dimensões formadoras próprias da educação popular. Arroyo (2017) discute uma concepção de EJA centrada na vida dos sujeitos, a partir de suas origens, de seu trabalho e de suas manifestações culturais. Uma vez que o modelo em curso nos municípios tende ao da escola tradicional, a avaliação não consegue ser diferenciada. Adotam-se desde reprodução de testes usados com crianças e adolescentes a provas. As matrizes acabam centradas nas relações geracionais, próprias da organização do ensino comum e não nas intergeracionais, próprias da EJA.

Além disso, observou-se nas escolas visitadas a dificuldade em mexer na disposição fixa das carteiras na sala de aula, o que não permite agrupamentos diferenciados. Belo Horizonte e Contagem, ao contrário, apresentam propostas pedagógicas que seguem matrizes curriculares diferenciadas dos demais municípios. Trabalham por áreas de conhecimento em que os professores assumem, de forma compartilhada, as disciplinas no interior de uma mesma área.

A respeito dos recursos didáticos, alguns gestores afırmam não identificar materiais próprios para a EJA. Encontram-se escolas que chegaram a iniciar o uso de livros didáticos oficiais de EJA, porém, sem continuidade, enquanto outras disponibilizam fontes para consulta de livros didáticos e paradidáticos. Cada vez mais gestores e educadores reconhecem a diversidade dos sujeitos da EJA que se torna elemento chave da proposta pedagógica. Se os sujeitos são diversos, faz sentido pensar e construir o material didático.

A questão tem sido debatida nos municípios e alguns adotam a produção própria e a adequação de atividades. Observa-se certo desconhecimento do que tem sido produzido na EJA a partir de seus protagonistas: Organizações não Governamentais - ONG/Movimentos Sociais, Municípios e Estado, como o Almanaque Aluá (desde 1993) da ONG Sapé; Cadernos Pedagógicos e Palavra do Trabalhador (desde 1993) da Secretaria Municipal de Educação de Porto Alegre; Cadernos de Produções Coletivas da Secretaria Municipal de Educação de Maceió (desde 1996); Educação de Jovens e Adultos - Proposta Curricular para o $1^{\circ}$ 
segmento, da Ação Educativa (1997) e Álbum Cultural do Recife (1998) da Secretaria de Educação da cidade do Recife, para citar alguns.

Um último fator que remete às políticas que acabam com a EJA diz respeito à frequente mudança nos cargos de gestão municipal. Em consequência, a composição dos quadros, inclui-se aí a coordenação da EJA, que opera com instabilidade em sua manutenção. A constituição das equipes e a continuidade do trabalho estão à mercê dos grupos instituídos na Secretaria pelo poder local a cada gestão de governo. Ao mesmo tempo em que há permanência de equipes em certos municípios, encontramos outros sem ao menos um coordenador de EJA e municípios com um único profissional responsável pela organização e pelo atendimento de EJA em toda sua extensão.

\section{Como tornei-me educador da Educação de Jovens e Adultos: "caí na EJA"}

0 tema da formação de educadores emergiu sob diversos aspectos nas reuniões com gestores e coordenadores municipais de EJA, ora para questionarem essa formação nos cursos de graduação, ora para citarem iniciativas das prefeituras, dos fóruns de EJA e das universidades em que se engajam. De modo geral, do ponto de vista da gestão, chegam à EJA professores com conhecimento de suas áreas, mas não das características dos sujeitos e nem de como aprendem. Pesquisas coincidem com as denúncias de gestores quanto à falta de estudos sobre as singularidades da escolarização de jovens e adultos durante a formação inicial, quer em estágio, quer em disciplina obrigatória (LAFFIN, 2012; PORCARO, 2011; CAMARGO, 2015; PEDROSO, 2015).

Essa realidade é uma crítica ao reduzido espaço da formação de educadores da EJA nos cursos de licenciatura das universidades brasileiras, conforme Soares (2008) e Laffın (2012). Os autores investigaram a presença da educação de jovens e adultos no ensino, na pesquisa e na extensão dos cursos de formação de educadores e constataram um percentual maior na matriz curricular dos cursos de Pedagogia que nas demais licenciaturas.

Estudos reconhecem que ser educador de jovens e adultos exige formação que trate das particularidades dos estudantes (ARROYO, 2006; SOARES, 2007; RIBEIRO, 1999; VÓVIO, 2010). Sem a garantia do espaço formativo nas licenciaturas, o educador encontrará dificuldades para lidar com as especificidades da modalidade como um todo, o que pode se transformar em um dos maiores impasses vividos na escola se ele chegar à EJA carregado das mesmas concepções que têm do ensino com crianças e adolescentes.

A análise de alguns gestores é a de que os "profissionais estão totalmente despreparados para trabalhar com EJA. São professores que pegam a EJA por pegar e é um despreparo total" (Gestor C), de tal modo que em alguns casos o "tipo de escola ofertada é uma réplica da do diurno que não tem atendido as especificidades do público" (Gestor A).

Em contrapartida, os educadores não negam a falta de conhecimento e a forma abrupta que entraram na EJA. A expressão "caí na EJA" como a forma como eles chegam à modalidade é uma analogia a "cair de paraquedas" e ambas dizem respeito ao ingressar em alguma situação sem conhecimento de causa do objeto. É dessa maneira que se sentem alguns educadores na medida em que confirmam: "Não fomos preparados! Falta formação inicial e continuada!" (Professor A). 
0 primeiro contato com a EJA, de acordo com maioria dos entrevistados, foi por acaso em algum momento da sua atuação profissional. Para outros, a EJA aparece como uma oportunidade de complementação de carga horária. Nos dois casos, após "caírem na EJA" e depararem-se com as complexidades e os desafios, é que buscam pela formação continuada. Desse movimento de chegada e de reconhecimento, resultam diferenciadas trajetórias de formação e de atuação profissional, ou seja, foram entender o que seria a EJA depois de aceitarem o cargo. Uma condição delicada para a escola, para o estudante e, sobretudo, para o próprio educador.

A categoria docente enfrenta salários defasados, precárias condições de trabalho e desvalorização da profissão. Em meio à situação, terminar a graduação e ingressar na pós-graduação implica esforços de tempo e investimento monetário. Por outro lado, a educação pública, gratuita e de qualidade é um direito de todos e somente a boa vontade dos educadores não é suficiente para garantir o exercício da profissão consequente às características dos demandantes jovens, adultos e idosos. De acordo com Freitas (2014) e Pedroso (2015), é grande o número de professores e gestores com pós-graduação, entretanto, são iniciantes nas discussões sobre a Educação de Jovens e Adultos.

De fato, quando analisada a fala dos gestores e a condição docente frente à composição multigeracional das salas de aula, percebe-se que os espaços de formação são fundamentais ao acompanhamento das resistências. Reconhecer a diferença dos públicos não basta para administrar disciplina e aprendizagem de jovens com os adultos e vice-versa.

A literatura denomina de fenômeno da juvenilização o processo de chegada dos jovens à EJA nos anos de 1990, tensionando a escola comum e a razão histórica da educação de adultos (ANDRADE, 2004; CARRANO, 2007; LEÃO, 2005). Ainda que os municípios tenham aderido a diferentes programas governamentais direcionados a jovens e adultos - desde o Mobral aos programas Recomeço ${ }^{11}$ e Aceleração de Aprendizagem (Projetos Travessia, Acertando o Passo e Caminho da Cidadania) - expressam dificuldade no acolhimento da juventude na EJA. Percebe-se que a imagem do jovem da EJA está colada ao seu comportamento e corre-se o risco de vê-lo somente de forma negativa. Ser jovem na/da EJA não se resume a um estereótipo, no caso, indisciplinado quando não violento (DAYRELL, 2005; CARRANO, 2007; ANDRADE, 2004).

$\mathrm{Na}$ outra margem estão os adultos/idosos com suas necessidades e seus interesses. Os professores reconhecem que o "adulto é mais difícil de alfabetizar porque eles têm mais dificuldade devido ao cansaço do dia a dia, apesar de terem vontade de aprender" (Professor C). Estudos sobre jovens e adultos, e a presente pesquisa corrobora, enfatizam uma formação sobre os modos reais de ser jovem/adulto/idoso como um caminho de possibilidades para reconhecer demandas, características e necessidades específicas desses grupos.

Ao exíguo estudo sobre a EJA apresentado pelos professores e gestores, acrescenta-se a necessidade deles complementarem a carga horária de trabalho em outra etapa da educação básica. Configuram-se, assim, professores que lecionam para crianças e adolescentes durante o dia e para jovens, adultos e idosos à noite. Destaca-se que "em virtude da ausência de políticas que articulem organicamente a educação de jovens e adultos às redes públicas

11- Programa Supletivo, regulamentado pelo Fundo Nacional de Desenvolvimento da Educação (FNDE/MEC), Resolução CD/ FNDE $n^{\circ} 10$ de 20 de março de 2001. Em 2003 foi renomeado para Programa Fazendo Escola. 
de ensino básico, não há carreira específica para educadores desta modalidade educativa" (DI PIERR0; GRACIANO, 2003, p. 23). Muitos docentes terminam por não criar vínculos permanentes com o campo em que atuam, vendo-se como passageiros, podendo deixar a EJA a qualquer momento ou a cada distribuição de horário de trabalho. Em razão dessa instabilidade profissional, o educador da EJA está à mercê do não pertencimento à área e reforça a ideia de estar na EJA como complementação de jornada.

Ainda que seja explícita, volumosa e esparsa a demanda por educação básica de jovens e adultos existente no Brasil, há poucas redes públicas de ensino que realizam concurso específico ao provimento da vaga de professor da EJA. Esse pode ser um impasse para a qualidade do trabalho com jovens e adultos. Por recrutar professores com parcos conhecimentos sobre a EJA, o poder local é responsável por propiciar momentos de formação continuada.

Nos municípios mineiros pesquisados, verifıcaram-se que a formação se acomoda de acordo com a realidade de cada um. A figura do coordenador de EJA nas secretarias municipal de educação parece ser decisiva. Faz parte da função dele buscar, organizar e fomentar o processo formativo, o qual varia de palestras, cursos, reuniões semanais, quinzenais ou mensais, a encontros por áreas de conhecimento. Começa a esboçar-se nos municípios um padrão de formação fixa às sextas-feiras. Em Belo Horizonte, por exemplo, uma das sextasfeiras fica a cargo das atividades propostas pela Secretaria Municipal de Educação e nas demais, a escola mesmo organiza a formação de acordo com a demanda. Outro exemplo de estratégia de formação é a criação de grupos de estudos com os educadores, como acontecem nos municípios de Acaiaca, Diogo de Vasconcelos e Itabirito.

\section{A respeito do "se jogar na EJA" ou como construir-se profissional da EJA}

No campo da EJA, a diversidade cultural relacionada à etária presente em sala de aula e suas peculiaridades pedagógicas esboçam-se aos educadores ao longo de suas experiências. Em seus depoimentos falam do conhecimento que vai sendo estabelecido pela relação entre eles e os dois conjuntos de estudantes com temporalidades da vida bem demarcadas. Alguns professores, após certo tempo de trabalho, criam identificação com os educandos e procuram permanecer na EJA. Chegam a afirmar que preferem a EJA e que se pudessem escolher, dedicar-se-iam só aos jovens, adultos e idosos e reforçam o comentário ao expressar que, com o "cair na EJA" passam a "se jogar na EJA".

"O perfil do educador de jovens e adultos e sua formação encontram-se ainda em construção", disse Miguel Arroyo por ocasião do I Seminário Nacional sobre a Formação de Educadores de Jovens e Adultos em 2006. Passada mais de uma década, a atualidade da afirmativa é confırmada por Di Pierro (2017), Laffın (2012), Vóvio (2010) dentre outros estudos recentes.

No Parecer CNE/CEB n 11/2000, que estabelece as Diretrizes Curriculares Nacionais para a Educação de Jovens e Adultos, quando se refere à formação do educador, lê-se "que o preparo de um docente voltado para a EJA deve incluir, além das exigências formativas para todo e qualquer professor, aquelas relativas à complexidade diferencial 
desta modalidade de ensino" (BRASIL, 2000, p. 52). Entretanto, não há menção nas normativas que tratam da EJA quais seriam as tais "exigências formativas". A questão tem sido sabatinada pelas universidades, enfaticamente, sobretudo nos Seminários Nacionais sobre Formação do Educador de Jovens e Adultos ${ }^{12}$ e a importância da formação está registrada nos documentos finais dos eventos.

Estudos buscam "as exigências formativas" a começar por distinguir o caráter peculiar da EJA antes de pensar o perfil do professor para ela. Ao conjunto de "exigências formativas" encontramos na literatura o termo "especificidades", que podem contribuir com a definição de matrizes formativas, quais sejam: a) legado da educação popular fortemente presente nas propostas curriculares; b) reconhecimento da diversidade cultural e etária dos sujeitos; c) tempos, espaços e avaliações diferenciadas; d) recursos didáticos próprios; e) busca de políticas públicas suplementares; e f) formação dos educadores apropriada para o público da EJA (SOARES; SOARES, 2014). Uma proposta pode valer-se desse apontamento.

Gestores e professores coincidem com a literatura quando fazem menções acerca da necessidade de construir-se um perfil do educador da EJA. Eles trazem elementos que auxiliam, como "um professor que tenha uma afinidade maior de trabalho com jovem" (Gestor C); "o professor que mais permite se aproximar - inclusive em termos de vocabulário - a eles, os jovens" (Gestor F) e "o professor que escolheu trabalhar na EJA, isso é fundamental" (Gestor A).

Mesmo tendo de enfrentar realidades tão distantes de sua formação, o professor atesta "nunca me senti tão importante quanto com esse tipo de público!" (Professor A). "A gente se sente como uma pessoa importante na vida daquela pessoa, é compensador!" (Professor C). "O aluno vê a EJA com um sentido mais amplo, que vai além da escolarização" (Professor D). "Eles têm gratidão pelo professor, mais do que os alunos do ensino fundamental regular" (Professor E).

De forma preliminar, o professor galga certa identificação com a EJA à medida que se estabelecem trocas de acolhimento. Pode-se dizer que o reconhecimento mútuo contribui para a construção da imagem do professor de jovens e adultos e para os vínculos de pertença à categoria. Vale ressaltar o esforço do professor para acercar-se dos estudantes, sobretudo dos jovens, por meio da linguagem. Lado a lado, os "saberes de experiência feitos” (FREIRE, 2002) do educando e do educador acolhem-se. Para Freire (2002, p. 53):

[...] é esta força misteriosa, às vezes chamada vocação, que explica a quase devoção com que a grande maioria do magistério nele permanece, apesar da imoralidade dos salários. E não apenas permanece, mas cumpre, como pode, seu dever.

Pode-se inferir que a afinidade com o público acaba por auxiliar na escolha pela área. Ainda que educadores de EJA das redes municipais pesquisadas apresentem reduzida formação específica sobre o campo, foram entrevistados número significativo deles com

12- Os seminários nacionais sobre a formação do educador de jovens e adultos (UFMG (Universidade Federal de Minas Gerais), 2006; UFG (Universidade Federal de Goiás), 2007; UFRGS (Universidade Federal do Rio Grande do Sul), 2010; BRASíLIA, 2012; CAMPINAS, 2015). 
mais de dez anos de experiência na EJA. Nesse caso, há que se considerar os saberes que adquiriram com a sala de aula quando afirmam "terem se jogado na EJA". Constatamse nos discursos dos educadores e nas observações em sala de aula elementos e práticas condizentes com as discussões teóricas do campo que visam a atender às particularidades dos educandos na parte pedagógica e cognitiva.

Tardif, Lessard e Lahaye (1991) nomearam aquele saber próprio da atuação do professor de saber docente. Esse saber seria composto por outros como o da sua formação profissional, o das disciplinas lecionadas, o do currículo advindo dos programas escolares e o de sua experiência propriamente dita. 0 saber da experiência é reconhecido como diferente dos demais, pois é formado por todos os outros, os quais nesse movimento são retraduzidos, reelaborados e submetidos às certezas construídas na prática e no vivido.

Segundo Schön (2000), quando os educadores refletem sobre a prática:

[...] sustentando uma conversação reflexiva com os materiais de suas situações, eles refazem parte de seu mundo prático e revelam, assim, os processos normalmente tácitos de construção de uma visão de mundo em que baseiam toda a sua prática. (SCHÖN, 2000, p. 39).

0 exercício diário daqueles que se jogam na EJA pelos estudos, pelas leituras e pelos planejamentos de aulas, acaba por comprometê-los e identificá-los com o trabalho.

Do ponto de vista profissional, "cair na EJA" vai contra o esperado de um educador. Entretanto, demonstra uma "situação limite" freireana (FREIRE, 1992) em que ele, por escolha própria ou não, vê-se impossibilitado de organizar-se dentro do contexto. Nesse ponto, os limites de várias ordens imobilizam a ação. Para alguns, o limite é intransponível. Para outros, não. Ao se verem na situação-limite, buscam maneiras de ultrapassar os obstáculos. É quando "se jogam na EJA”. Esse movimento de romper com o determinismo é "inédito viável" (FREIRE, 1992). Jogando-se na EJA, o educador reverte um quadro crítico de trabalho e, em contraponto, opera na margem das possibilidades, segundo Pinto (1960) endossado por Paulo Freire (1992).

\section{Apontamentos}

Tendo em vista a expectativa de aumento das matrículas na EJA com a criação do FUNDEB e a realização no Brasil da Confintea VI, constata-se, de forma controversa, o declínio da procura que vinha ocorrendo nas turmas de EJA. Dos municípios, espera-se que efetivem a escola pública de qualidade. Buscamos nesta pesquisa compreender como e de que maneira tem se dado a oferta da EJA no âmbito municipal em Minas Gerais.

A pesquisa junto ao poder local produziu dados quanti-qualitativos que nos ajudaram a superar impressões vagas quando se refere às estatísticas de EJA no que diz respeito aos números da oferta e da demanda potencial para a EJA e dois enfoques principais que foram aprofundados: "a EJA vai acabar" e "caí na EJA". Enfoques esses polissêmicos que aqui foram compreendidos pelo viés crítico de suas ressonâncias. "A EJA vai acabar" é uma narrativa que perpassa gestores e coordenadores e está sendo produzida em ações de políticas públicas restritivas do direito. Portanto, a EJA pode acabar não por falta de estudantes, como demonstrado acima, mas por falta de vontade política. 
A maneira como a esfera municipal tem arcado com a municipalização dos serviços educacionais, sem a devida colaboração entre os entes estadual e federal, reduz a EJA a ofertas insuficientes tendo em vista a demanda represada. Para tanto, recomenda-se aos espaços coletivos - fóruns estaduais e regionais - que exerçam sua atuação cada vez mais próxima da elaboração das políticas públicas para a EJA na esfera local. Aos gestores e coordenadores que não se imobilizem diante dos dados e, sim, atuem em direção à busca ativa do público da EJA. Assim, segundo Freire (2002), constatem para a mudança e não para a acomodação.

A expressão "caí na EJA" revela certo descuido dos gestores e coordenadores de EJA face aos desafios colocados para um docente que vai assumir a EJA. Sem a garantia do espaço formativo nas licenciaturas, o educador encontrará dificuldades para lidar com as especificidades da modalidade como um todo e isso pode se transformar em um dos maiores impasses vividos na escola se ele chegar à EJA carregado das mesmas concepções que têm do ensino com crianças e adolescentes.

Em outra direção, encontramos educadores que se identificam com os sujeitos e suas trajetórias, procuram se envolver com atividades de formação e dizem não querer sair da EJA. É o caso do educador que "se joga na EJA". Pode-se inferir que se dedicar ao trabalho seria uma atitude que diferencia um educador dos demais. Nesse caso, é importante que os municípios induzam políticas de formação continuada e que pensem na viabilidade de realizar concurso público ao provimento do cargo de professor da EJA o que evitaria o "cair na EJA".

Enquanto se aguarda a realização de concurso, recomenda-se estabelecer alguns critérios de seleção que valorizem, dos interessados no cargo, os estudos, a experiência e o envolvimento nas ações em EJA realizados. Tais apontamentos asseguram que a EJA tenha especificidades na oferta tais como prescritas na literatura da área. Além disso, tanto o Parecer n. 11/2000 quanto a LDB n 9.394/1996 reforçam o caráter singular da EJA por meio de expressões como adequado, apropriados, características, especificidade própria, modelo pedagógico próprio, voltado para e específica. De forma sintética, especificidade é a convergência de aspectos que capacitam a agir do modo próprio, produzindo algo peculiar, particular (SOARES; SOARES, 2014). Atendendo às especificidades da EJA, tem-se qualidade do serviço público de educação. As especificidades estabelecem-se no diálogo entre a realidade e sua análise crítica, portanto, carregam consigo a esperança de que "mudar é difícil, mas é possível” (FREIRE, 2002, p. 88).

\section{Referências}

ANDRADE, Eliane R. Os jovens da EJA e a EJA dos jovens. In: BARBOSA, Inês 0.; PAIVA, Jane (org.). Educação de Jovens e Adultos. 1. ed. Rio de Janeiro: DP\&A, 2004. p. 43-54.

ARROYO, Miguel. Passageiros da noite: do trabalho para a EJA. Itinerários pelo direito a uma vida justa. 1. ed. Petrópolis: Vozes, 2017.

ARROYO, Miguel. Ofício de mestre: imagem e auto-imagem. 10. ed. Petrópolis: Vozes, 2008. 
ARROYO, Miguel. Formar educadoras e educadores de jovens e adultos. In: SOARES, Leôncio. Formação de educadores de Jovens e Adultos. 1. ed. Belo Horizonte: Autêntica: SECAD-MEC/UNESCO, 2006. p. 17- 32.

BEISIEGEL, Celso R. A qualidade do ensino na escola pública. 1. ed. Brasília, DF: Líber Livro, 2006.

BÉLANGER, Paul. De la palabra a los hechos. Revista EAD: Educación de Adultos y Desarrollo, Bonn, n. 75, p. 59-68, 2010.

BRASIL. Governo Federal. Lei de Diretrizes e Bases da Educação Nacional. Lei n. 9.394, de 20 de dezembro de 1996. Brasília, DF: Governo Federal, 1996.

BRASIL. Instituto Nacional de Estudos e Pesquisas Educacionais Anísio Teixeira. Resumo técnico censo 2009. Brasília, DF: Ministério da Educação, 2010. Disponível em: http://download.inep.gov.br/download/ superior/censo/2009/resumo_tecnico_2009.pdf. Acesso em: 10 out. de 2019.

BRASIL. Ministério da Educação. Diretrizes curriculares nacionais para a educação de jovens e adultos: Resolução CNE/CEB Parecer 11/2000. Brasília, DF: MEC, 2000. Homologação publicada no Diário Oficial da União de 9/6/2000, Seção 1e, p. 15.

CAMARG0, Poliana. Representações sociais de professores da educação de jovens e adultos: EJA sobre sua formação docente e a afetividade no processo de ensino-aprendizagem. 2015. Tese (Doutorado em Educação) - Faculdade de Educação, Universidade Estadual de Campinas, Campinas, 2015.

CARRANO, Paulo C. Educação de jovens e adultos e juventude: 0 desafio de compreender os sentidos da presença dos jovens na escola da "segunda chance". REVEJ@, Belo Horizonte, v. 1, p. 1-11, ago. 2007.

CATELLI JR, Roberto; SERRÃO, Luís Felipe S. O ENCCEJA no cenário das políticas de educação de jovens e adultos no Brasil. In: CATELLI JR, Roberto et al., (org.). EJA em xeque: desafios das políticas de educação de jovens e adultos no século XXI. 1. ed. São Paulo: Global: Ação Educativa, 2014. p. 77-159.

CEDI. Centro Ecumênico de Documentação e Informação. Educação de jovens e adultos: subsídios para elaboração de políticas municipais. São Paulo: CEDI, 1990. (Documentos; 5).

CUNHA, Alda M. B.; RODRIGUES, Maria E.; MACHADO, Maria M. Alfabetização de jovens e adultos: políticas públicas e movimento popular. Cadernos Cedes, Campinas, v. 27, n. 71, p. 19-38, jan./abr. 2007.

DAYRELL, Juarez. Juventude, produção cultural e educação de jovens e adultos. In: SOARES, Leôncio et al. (org.). Diálogos na educação de jovens e adultos. 1. ed. Belo Horizonte: Autêntica, 2005. p. 69-83.

DI PIERRO, Maria Clara (org.). Um estudo sobre centros públicos de educação de jovens e adultos no Estado de São Paulo. 1. ed. São Paulo: FEUSP, 2017.

DI PIERRO, Maria Clara; GRACIANO, Mariângela. A educação de jovens e adultos no Brasil. São Paulo: Ação Educativa, 2003. 54 p. (Texto técnico). Informe apresentado à Oficina Regional da UNESCO para América Latina y Caribe. 
FÁVERO, Osmar; RUMMERT, Sônia M.; VARGAS, Sonia M. Formação de profissionais para a educação de jovens e adultos trabalhadores. Educação em Revista, Belo Horizonte, n. 30, p. 39-49, 1999.

FREIRE, Paulo. Pedagogia da autonomia: saberes necessários à prática pedagógica. 21. ed. São Paulo: Paz e Terra, 2002.

FREIRE, Paulo. Pedagogia da esperança: um reencontro com a pedagogia do oprimido. 13. ed. São Paulo: Paz e Terra, 1992.

FREITAS, Angelita A. A. Professores iniciantes na educação de jovens e adultos: por que ingressam? 0 que os faz permanecer? 2014. Dissertação (Mestrado em Educação) - Departamento de Educação, Universidade Federal de Ouro Preto, Mariana, 2014.

GOLDEMBERG, José. Agora tem professor no MEC. Jornal do Brasil, Rio de Janeiro, Ed. 136, Cad. 1Política e governo, p. 4, 22 de agosto de 1991.

HADDAD, Sérgio. A participação da sociedade civil brasileira na educação de jovens e adultos e na CONFINTEA VI. Revista Brasileira de Educação, Rio de Janeiro, v. 14, n. 41, p. 355-369, maio/ago. 2009.

HADDAD, Sérgio. Ensino supletivo no Brasil: o estado da arte. Brasília, DF: INEP, 1987. 134 p. (Texto técnico). HADDAD, Sérgio. Novos caminhos em Educação de Jovens e Adultos - EJA. 1. ed. São Paulo: Global, 2007. IRELAND, Timothy. Revisitando a CONFINTEA: sessenta anos de defesa e promoção da educação de adultos. Revista Brasileira de Educação de Jovens e Adultos, Salvador, v. 1, n. 1, p.14-28, 2013.

LAFFIN, Maria Hermínia L. Fernandes. A constituição da docência na educação de jovens e adultos. Currículo sem Fronteiras, Pelotas, v. 12, n. 1, p. 210-228, jan./abr. 2012.

LEÃO, Geraldo M. Políticas de juventude e educação de jovens e adultos: tecendo o diálogo a partir dos sujeitos. In: SOARES, Leôncio et al. Diálogos na educação de jovens e adultos. 1. ed. Belo Horizonte: Autêntica, 2005. p. 69-83.

LEMME, Paschoal. Educação supletiva/educação de adultos. In: LEMME, Paschoal. Memórias de um educador. 2. ed. Brasília, DF: INEP, 2004. p. 41-88. (Estudos, educação e destaques da correspondência; v.5).

MINAS GERAIS. Resolução SEE N$^{\circ}$ 2.843, de 13 de janeiro de 2016. Dispõe sobre a Organização e 0 Funcionamento da Educação de Jovens e Adultos/EJA - cursos presenciais, nas escolas da rede pública estadual de Minas Gerais. Belo Horizonte: Secretaria de Estado de Minas Gerais, 2016. Disponível em: http://sindutemg.org.br/wp-content/uploads/2017/11/RESOLU\%C3\%87\%C3\%830-SE E-N\%C2\%BA2.843-DE-13-DE-JANEIRO-DE-2016.pdf. Acesso em: 10 out. de 2019.

MINAS GERAIS. Resolução SEE N 9.298, de 09 de janeiro de 1998. Institui o Projeto Travessia, implantando a estratégia pedagógica de aceleração de estudos, destinada a alunos do $1^{\circ}$ Ciclo do Ensino Fundamental, noturno, fora da faixa etária, em escolas da Rede Estadual de Ensino. Diário Oficial de Minas Gerais, 13 fev. 1998. Disponível em: https://docs.wixstatic.com/ugd/6c6b12_c7f20325fbc543419cc7b88c17a1abbd. pdf. Acesso em: 10 de out. 2019. 
MINAYO, Maria Cecília S.; SANCHES, Odécio. Quantitativo-qualitativo: oposição ou complementaridade? Cadernos de Saúde Pública, Rio de Janeiro, v. 9, n. 3, p. 239-262, jul/sep, 1993.

MOLL, Jaqueline; VIVIAN, Danise. Institucionalização e criação na EJA: perscrutando caminhos afirmativos no Centro Municipal dos Trabalhadores Paulo Freire em Porto Alegre. In: HADDAD, Sérgio (org.). Novos caminhos em Educação de Jovens e Adultos - EJA. 1. ed. São Paulo: Global, 2007. p. 27-49.

PAIVA, Jane. Tramando concepções e sentidos para redizer o direito à educação de jovens e adultos. Revista Brasileira de Educação, Rio de Janeiro, v. 11, n. 33, p. 519-566, set./dez. 2006.

PEDROSO, Ana Paula. Trajetórias formativas de educadores da EJA: fios e desafios. 2015. Tese (Doutorado em Educação) - Faculdade de Educação, Universidade Federal de Minas Gerais, Belo Horizonte, 2015.

PORCARO, Rosa. Caminhos e desafios da formação de educadores de jovens e adultos. 2011. Tese (Doutorado em Educação) - Faculdade de Educação, Universidade Federal de Minas Gerais, Belo Horizonte, 2011.

PINTO, Álvaro V. Consciência e realidade nacional. v. 2. Rio de Janeiro: ISEB, 1960.

RIBEIRO, Vera Masagão. A formação de educadores e a constituição da educação de jovens e adultos como campo pedagógico. Educação \& Sociedade, Campinas, v. 20, n. 68, p. 184-201, dez. 1999.

SCHÖN, Donald. Educando o profissional reflexivo: um novo design para o ensino e a aprendizagem. Trad. Roberto Cataldo Costa. Porto Alegre: Artmed, 2000.

SILVA, Fernanda Aparecida 0. Rodrigues. Tópicas em história recente da EJA: a formação pela vivência e convivência nos fóruns regionais mineiros. 203 f. 2018. Dissertação. (Mestrado em Educação) - Faculdade de Educação, Universidade Federal de Minas Gerais, Belo Horizonte, 2018.

SILVA, Fernanda Aparecida 0. Rodrigues; SOARES, Leôncio. Educação de Jovens e Adultos: preparando a VI CONFINTEA pensando o Brasil. Revej@, Belo Horizonte. v. 02, p. 01-15, 2008.

SOARES, Leôncio. Educador de jovens e adultos em formação. Educação em Revista, Belo Horizonte, n. 47, p. 83-100, 2008

SOARES, Leôncio; SILVA, Fernanda Aparecida 0. Rodrigues. As especificidades da Educação de Jovens e Adultos nas escolas públicas como indicadores de saberes necessários à formação do educador de jovens e adultos. Belo Horizonte: CNPQ, 2018. 137 p. (Texto técnico).

SOARES, Leôncio; SOARES, Rafaela. 0 reconhecimento das especificidades da Educação de Jovens e Adultos: constituição e organização de propostas de EJA. Archivos Analíticos de Políticas Educativas/ Education Policy Analysis Archives, Tempe City, v. 22, n. 66, p. 1-21, 2014.

SOARES, Leôncio; VENÂNCIO, Ana. Tensões, contradições e avanços: a educação de jovens e adultos em uma escola municipal de Belo Horizonte. Educar em Revista, Curitiba, v. 29, p. 141-156, 2007. n. 29. 
TARDIF, Maurice; LESSARD, Claude; LAHAYE, Louise. Os professores face ao saber: esboço de uma problemática do saber docente. Teoria \& Educação, Porto Alegre, n. 4, p. 215-233, 1991.

UNESCO. Marco de ação de Belém. In: CONFERÊNCIA INTERNACIONAL DE EDUCAÇÃO DE ADULTOS, 6., 2010. Brasília, DF: UNESCO/MEC, 2010. 25 p.

VOLPE, Geruza. 0 financiamento da educação de jovens e adultos no período de 1996 a 2006: farelos de migalhas. 2010. Tese (Doutorado em Educação) - Faculdade de Educação, Universidade Estadual de Campinas, Campinas, 2010.

VóvI0, Cláudia. Formação de educadores de jovens e adultos: a apropriação de saberes e práticas conectadas à docência. In: SOARES, Leôncio et al. (org.). Convergências e tensões no campo da formação e do trabalho docente. 1. ed. Belo Horizonte: Autêntica, 2010. p. 60-77.

Recebido em: 22.08.2019

Revisado em: 08.10.2019

Aprovado em: 22.10.2019

Fernanda Aparecida Oliveira Rodrigues Silva é professora adjunta da Universidade Federal de Ouro Preto com pós-doutoramento pela Universidade de São Paulo com parte na University of Wisconsin-Madison, Estados Unidos (2019-2020). Pesquisa e publica na área de educação, com ênfase em Educação de Jovens e Adultos.

Leôncio Soares é professor titular da Universidade Federal de Minas Gerais com pósdoutoramento na Universidade Federal Fluminense (2006) e na Northern Illinois University, Illinois, Estados Unidos (2012-2013). Pesquisa e publica na área de educação, com ênfase em Educação de Jovens e Adultos. 